Témoigner Témoigner. Entre histoire et mémoire

Getuigen Revue pluridisciplinaire de la Fondation Auschwitz

$115 \mid 2013$

L'Espagne en construction mémorielle

\title{
Le crime contre l'humanité, une étude critique
}

The crime against humanity, a critical study

Misdaad tegen de menselijkheid, een kritische studie

Florent Bussy

\section{OpenEdition}

Journals

Édition électronique

URL : https://journals.openedition.org/temoigner/528

DOI : $10.4000 /$ temoigner.528

ISSN : 2506-6390

Éditeur :

Éditions du Centre d'études et de documentation Mémoire d'Auschwitz, Éditions Kimé

Édition imprimée

Date de publication : 1 mars 2013

Pagination : 135-148

ISBN : 978-2-84174-628-6

ISSN : 2031-4183

Référence électronique

Florent Bussy, «Le crime contre l'humanité, une étude critique », Témoigner. Entre histoire et mémoire

[En ligne], 115 | 2013, mis en ligne le 01 juin 2015, consulté le 21 septembre 2021. URL : http:// journals.openedition.org/temoigner/528 ; DOI : https://doi.org/10.4000/temoigner.528 


\section{Le crime contre l'humanité, une étude critique}

FLORENT BUSSY

Université de Rouen

\section{HISTOIRE DE LA NOTION}

\section{Les origines : la référence à l'humanité dans le droit international}

Les origines de la notion de crime contre l'humanité révèlent son appartenance au droit international. C'est en effet pour le procès de Nuremberg qu'elle trouve sa première codification juridique officielle. Le tribunal des nations alliées y a jugé les actes causés pendant la Seconde Guerre mondiale par les nazis, dans un cadre discriminatoire, en plus des crimes de guerre et des crimes contre la paix.

Auparavant, en 1868, la Déclaration de Saint-Pétersbourg condamnait les souffrances inhumaines infligées à l'ennemi et l'utilisation des projectiles explosifs et incendiaires comme étant contraires aux lois de l'humanité. En 1899, la Clause de Martens, concernant les lois et coutumes de la guerre sur terre, parlait des lois de l'humanité ; mais la référence à ces « lois » servait à condamner les « crimes de guerre » et non les « crimes contre l'humanité ».

C'est en 1915, pendant la Première Guerre mondiale, que l'expression de « crime contre l'humanité » apparaît pour la première fois, au moment du génocide des Arméniens de Turquie. Au mois de mai, la Russie, la France et la Grande-Bretagne dénoncent en effet les massacres comme des « crimes contre l'humanité et la civilisation » ou des « crimes de lèse-humanité ». Le gouvernement turc accuse alors les puissances de l'Entente de les avoir rendus inévitables en organisant le mouvement révolutionnaire arménien pour affaiblir le pays en période de guerre. L'idée de crime contre l'humanité est formulée en réaction à des actes inhumains qui ne correspondent pas à une dérive militaire (crimes de guerre), mais qui visent la mort ou la persécution de populations civiles embarrassantes pour le pouvoir.

Le génocide des Arméniens et le génocide des Juifs sont donc à l'origine de l'apparition de la notion, laquelle est pourtant plus large que le génocide qui en est la forme la plus extrême. En effet, l'humanité peut être visée par un crime, sans que cela se réalise sous la forme de l'extermination d'un groupe humain. 


\section{Les crimes nazis}

Lidée de juger les crimes nazis est apparue rapidement au cours de la guerre. Dans la Déclaration de Saint-James signée à Londres, le 13 janvier 1942, les Alliés (neuf signataires) prévoient de réprimer les forfaits contre les populations civiles « qui n'ont rien de commun ni avec la notion d'actes de guerre, ni avec celle de crimes politiques telles que les conçoivent les nations civilisées. » La Déclaration de Moscou du 30 octobre 1943 signée par Churchill, Staline et Roosevelt indique que « les trois puissances alliées les poursuivront [les Allemands qui auront trempé leurs mains dans le sang innocent] jusqu'au bout de la terre et les remettront aux mains de leurs accusateurs pour que justice soit faite. »

À la fin de la guerre, la découverte des camps de concentration et d'extermination, dont l'existence était connue depuis 1942, a conduit les Alliés à la mise en place d'un tribunal international pour le jugement des criminels nazis. C'est l'Accord de Londres du 8 août 1945 qui fixe le statut du tribunal de Nuremberg et la première définition juridique du crime contre l'humanité. Les crimes contre l'humanité apparaissent à la suite des crimes d'agression et des crimes de guerre et sont donc situés à un second plan par rapport à ce qui concerne la guerre et son déclenchement.

Linculpation de « crimes contre l'humanité » est nouvelle, contrairement aux deux autres ; est neuve également l'institution d'un tribunal international jugeant des crimes d'État. Tous les projets étaient, depuis la Première Guerre mondiale, restés lettre morte, notamment celui, présent dans le Traité de Versailles, de jugement de l'Empereur Guillaume II pour « offense suprême contre la morale internationale et l'autorité sacrée des traités. » De même, le Traité de Sèvres (1920) prévoyait l'extradition par la Turquie des responsables du génocide arménien. Le problème de la coopération internationale était déterminant: la Hollande qui avait donné refuge au Kaiser, refusait de l'extrader et la Turquie a toujours refusé de reconnaître le génocide des Arméniens.

\section{Le sens de l'inculpation de Nuremberg}

Article 6-c:

Les Crimes contre l'Humanité : c'est-à-dire l'assassinat, l'extermination, la réduction en esclavage, la déportation, et tout autre acte inhumain commis contre toutes populations civiles, avant ou pendant la guerre, ou bien les persécutions pour des motifs politiques, raciaux ou religieux, lorsque ces actes ou persécutions, qu'ils aient constitué ou non une violation du droit interne du pays où ils ont été perpétrés, ont été commis à la suite de tout crime rentrant dans la compétence du Tribunal, ou en liaison avec ce crime.

L'inculpation de Nuremberg ne fait pas référence à des crimes commis individuellement pour des motifs classiques liés à l'intérêt ou au désir de puissance. Il s'agit de crimes collectifs, commis « pour des motifs politiques, raciaux ou religieux. » L'inculpation fait donc référence à une dimension discriminatoire, puisqu'elle parle de « motifs politiques, raciaux ou religieux », ce qui signifie que les assassinats, les 
déportations, les persécutions jugés dans le cadre du crime contre l'humanité sont commis contre des populations en raison de leur appartenance à un groupe racial, politique ou religieux. Tombent donc sous cette inculpation les actes de génocide contre les Juifs (religion, race), contre les Tsiganes (race), les persécutions contre les communistes allemands, contre les Témoins de Jéhovah. L'assassinat de masse des prisonniers russes (pourtant présentés par les nazis comme appartenant à un plan de guerre raciale) sera au contraire qualifié de « crime de guerre ».

\section{L'élargissement de l'inculpation}

La notion de crime contre l'humanité est en évolution depuis son origine. Dès la loi du Conseil de contrôle allié pour l'Allemagne de décembre 1945, sa définition le sépare des crimes de guerre et d'agression. « Crimes contre l'humanité. Atrocités et délits comprenant, sans que cette énumération soit limitative, l'assassinat, l'extermination, l'asservissement, la déportation, l'emprisonnement, la torture, le viol ou tous autres actes inhumains commis contre toute population civile et les persécutions, pour des motifs d'ordre politique, racial ou religieux, que lesdits crimes aient constitué ou non une violation de la loi nationale dans le pays où ils ont été perpétrés. »

L'évolution de la notion est importante jusqu'au Statut de Rome (1998) qui institue la Cour pénale internationale (CPI). Les législations nationales ont généralement adopté la définition de Nuremberg, mais le statut de ce crime varie. Il est le seul crime imprescriptible pour le droit pénal français contrairement au droit international qui soumet également les crimes de guerre au régime de l'imprescriptibilité (Convention de 1968 non ratifiée par la France).

La CPI a élargi la définition de l'inculpation d'une manière adéquate à la multiplicité des crimes qui visent l'humanité des hommes.

Article 7 Crimes contre l'humanité :

1. Aux fins du présent Statut, on entend par crime contre l'humanité l'un quelconque des actes ci-après lorsqu'il est commis dans le cadre d'une attaque généralisée ou systématique lancée contre toute population civile et en connaissance de cette attaque : a) Meurtre b) Extermination c) Réduction en esclavage d) Déportation ou transfert forcé de population e) Emprisonnementf) Torture g) Viol, esclavage sexuel, prostitution forcée, grossesse forcée, stérilisation forcéeh) Persécution de tout groupe ou de toute collectivité identifiable pour des motifs d'ordre politique, racial, national, ethnique, culturel, religieux ou sexiste ou en fonction d'autres critères universellement reconnus comme inadmissibles en droit international i) Disparitions forcées de personnes j) Crime d'apartheid k) Autres actes inhumains de caractère analogue causant intentionnellement de grandes souffrances ou des atteintes graves à l'intégrité physique ou à la santé physique ou mentale.

(1)William Bourdon, Emmanuelle Duverger, La Cour pénale internationale, Le statut de Rome, Paris, Seuil, 2000, p. 41-42. 
Les crimes poursuivis ne renvoient apparemment pas tous à une discrimination, puisque les motifs discriminatoires (h) ne concernent que les persécutions, lesquelles sont toutefois très élargies. Pourtant, il faut toujours que le crime soit commis « dans le cadre d'une attaque généralisée ou systématique lancée contre toute population civile et en connaissance de cette attaque », pour être défini comme un crime contre l'humanité. Le terme « généralisé » fait référence au caractère massif de l'acte. Le terme « systématique » à un plan méthodique. Lalternative « ou » semble toutefois indiquer qu'un meurtre massif pourrait être, en tant que tel, un crime contre l'humanité.

Mais le paragraphe 2 a) précise que «par "attaque lancée contre une population civile” on entend le comportement qui consiste en la commission multiple d'actes à l'encontre d'une population civile quelconque, en application ou dans la poursuite de la politique d'un État ou d'une organisation ayant pour but une telle attaque. » Cela signifie qu'est visée une population civile pour ce qu'elle est. On retrouve, de ce fait, la discrimination qui semblait avoir disparu dans le paragraphe 1. Parce que si une population est attaquée pour elle-même, c'est pour des raisons discriminatoires. Cette discrimination relève de la politique d'un État et correspond donc nécessairement à une planification systématique.

Par ailleurs, les formes de la discrimination ont considérablement évolué depuis Nuremberg. Elles sont « d'ordre politique, racial, national, ethnique, culturel, religieux ou sexiste. » (1. h) Dans ce cadre, la persécution par les talibans des femmes afghanes constitue un crime contre l'humanité. Lélargissement est potentiellement indéfini, le texte ajoutant « ou en fonction d'autres critères universellement reconnus comme inadmissibles en droit international. » L'inculpation peut ainsi inclure des discriminations d'ordre intellectuel, idéologique, social ou culturel.

\section{Le sens du crime contre l'humanité}

Les changements dans la définition ne permettent toutefois pas de dire qu'il y a un bouleversement. Il y a au contraire une continuité entre Nuremberg et la CPI.

Seule véritable parenthèse dans cette continuité, le statut du TPIY (Tribunal pénal international pour l'ex-Yougoslavie) qui parle d'actes « dirigés contre une population civile quelle qu'elle soit. » On assiste à une banalisation de la notion. La condition discriminatoire disparaît, on n'a plus affaire à une politique systématique de persécution ou d'extermination. Yann Jurovics dit même que c'est la condition politique qui est alors occultée, le crime contre l'humanité n'étant plus nécessairement un crime d'État ${ }^{2}$.

(2) « Le statut du TPIY permet alors d'utiliser le crime contre l'humanité comme rempart contre toute "barbarie" contre toute atteinte massive aux droits de l'homme, in fine comme protection des valeurs humaines de la civilisation, et non plus pour protéger l'humanité contre les seules politiques criminelles discriminatoires. » (Yann Jurovics, Réflexions sur la spécificité du crime contre l'humanité, Paris, Librairie Générale de Droit et de Jurisprudence, 2002, p. 191-192.) 